\title{
Development of university public transport monitoring system with mobile communication application
}

\author{
Khairul Kamarudin Hasan ${ }^{1}$, , Kamaru Adzha Kadiran ${ }^{1}$, Yusmarnita Yusop ${ }^{2}$, Muhammad Asraf Hairuddin ${ }^{1}$, Sufian \\ Mohamad $^{1}$
}

${ }^{1}$ Faculty of Electrical Engineering, Universiti Teknologi Mara, Cawangan Johor, Kampus Pasir Gudang, Johor, Malaysia 2Faculty of Electronic and Computer Engineering, Universiti Teknikal Malaysia, Melaka, Malaysia

\section{ARTICLE INFO}

Article history:

Received 7 March 2017

Received in revised form

14 June 2017

Accepted 17 June 2017

Keywords:

Public transport

Monitoring system

Mobile communication application

\begin{abstract}
A B S T R A C T
This project objective is to develop the system for university bus transportation monitoring purpose so that students waiting time could be reduced. The system consists of three main parts, a high-frequency radio module, the microcontroller systems and GSM modem. The microcontroller is also equipped with LCD display, buzzer and LED. Digital display board is placed at the waiting platform to show the approximate bus arrival time to the destination. Students also will received notification via SMS notifying on the status of the whereabouts of the shuttle bus without worrying of missing the bus. At the end of the project, students will be able to estimate bus current location from the short-messaging service received or from the display board at waiting platform. Hence, the project could help to minimize waiting time of the students at the shuttle bus waiting platform. It is also aimed to improve the management of existing bus transportation monitoring system in the university by using combination of GSM technology and microcontroller.
\end{abstract}

(C) 2017 The Authors. Published by IASE. This is an open access article under the CC BY-NC-ND license (http://creativecommons.org/licenses/by-nc-nd/4.0/)

\section{Introduction}

Transportation is the systems and modes of conveyance of people and goods from place to place. The purpose of transportation planning is to provide faster, safer, more efficient and more pleasant travel. Inconsistence bus arrival schedule in university usually will cause students' valuable time being wasted at shuttle bus waiting platform. This system can provide priority and a complete schedule in order to improve bus operation without making any changes to the existing routes or management systems. As a result, students can use their time for other purposes such as meet their lecturers or go to library while aware of the actual bus arrival time. The digital display board placed at the waiting platform will show the distance and estimated bus arrival time. Several researches have been conducted related to transport monitoring system. Juhari and Mansor (2016) had used Arduino UNO as microcontroller, GPS and GSM as the tracking and communication system. The location data was then

\footnotetext{
* Corresponding Author.

Email Address: khairul@johor.uitm.edu.my (K. K. Hasan) https://doi.org/10.21833/ijaas.2017.07.021

2313-626X/C) 2017 The Authors. Published by IASE.

This is an open access article under the CC BY-NC-ND license

(http://creativecommons.org/licenses/by-nc-nd/4.0/)
}

sent to web server. The website shows university campus road map on Google Maps with the location marks as pointer indicating current location. As a result, people can know the exact location of the bus in real-time manner. Meanwhile, Lau (2013) proposed bus vehicle tracking in UCSI University, Kuala Lumpur. It is implemented for fixed route and provides the status of the bus after specific time interval using outdoor LED panel at the bus stop. Same information in text and voice format can be retrieved through smart phone and Interactive Voice Response (IVR) system for students that are not nearby bus stop. This paper is organized into several sections mainly to discuss on methodology, system block diagram, microcontroller, GSM, result and analysis and conclusion.

\section{Methodology}

Generally, the system block diagram is divided into hardware and software part depicted as in Fig. 1. The flow started when the device located in the bus shuttle transmits the signal to receiver at platform to inform the current location. Receiver at platform process data and displays it on the display platform and then sends the notification to students through GSM modem. The PIC circuit is used to control the timing on sending massage by GSM 
module. The software part will implement the program instruction as desired by the flow of the operation system.

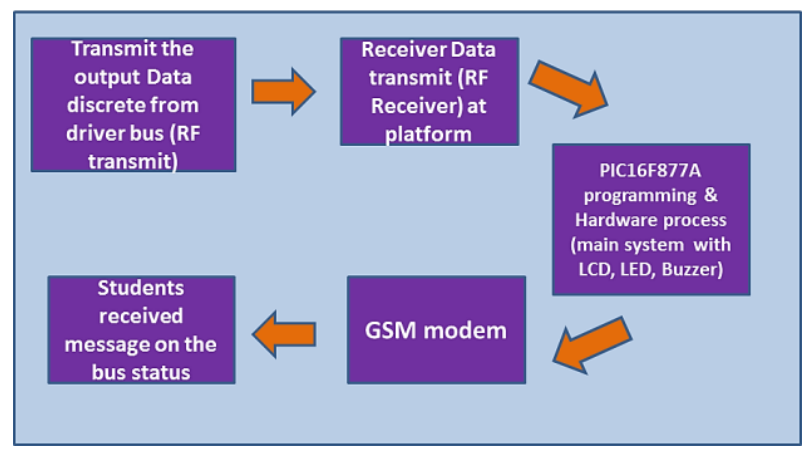

Fig. 1: System block diagram

\subsection{System block diagram}

The literature review and background on this project has been covered by referring various references including books, IEEE's journals as well as websites on PIC. In the following order, all information related to components, RF application and the suitable GSM modem's information will be selected to ensure that the project is work as expected. For the next stage, PIC programming is developed and tested in Proteus software to program PIC microcontroller to ensure programming is able to execute in the equipment application. For final stage, hardware for the project is setup, and the system is prepared for overall system validation.

\subsection{Microcontroller}

A microcontroller is a functional computer system-on-a-chip which contains a processor core, memory, and programmable input/output peripherals (Ananthanarayanan, 2013). Microcontrollers include an integrated CPU, memory (a small amount of RAM, program memory, or both) and peripherals capable of input and output. It emphasizes high integration, in contrast to a microprocessor which only contains a CPU (the kind used in a PC). In addition to the usual arithmetic and logic elements of a general purpose microprocessor, the microcontroller integrates additional elements such as read-write memory for data storage, readonly memory for program storage, Flash memory for permanent data storage, peripherals, and input/output interfaces (Misran et al., 2014). By reducing the size, cost, and power consumption as compared to the design that use separate microprocessor, memory, and input/output devices, microcontrollers make it economical to electronically control many more processes (Hao and Foster, 2008). PIC 16F877A can be used for controlling home appliances, remote sensors, industrial instruments, electrical door locks and safety devices.

In this project, the chip only needs $5 \mathrm{~V}$ power supply adapter, a $20 \mathrm{MHz}$ crystal oscillator and 2 units of $33 \mathrm{pF}$ capacitors to make it work. It can be programmed and erased up to 10,000 times which makes it useful for new product development phase. EEPROM memory makes microcontroller applicable to devices where permanent storage of many parameters needed. It is also very easy to be assembled.

The chip has two types of internal memories, program memory and data memory. Program memory is provided by $8 \mathrm{~K}$ words of flash memory and data memory has two sources. One types of data memory is 368-byte RAM and the other is 256-byte EEPROM. The core feature includes interrupt capability up to 14 sources, power saving sleep mode and single 5V In-Circuit Serial Programming (ICSP) capability. The sink or source current, which indicates a driving power from I/O port, is high with 25mA (Peatman, 1997).

Power consumption is less than $2 \mathrm{~mA}$ in $5 \mathrm{~V}$ operating condition. Its packs into 40 -pin package with 4 ports used for input/output called Port A, Port B, Port C and Port D (Giurgiutiu, 2009). As example, the connection for this project uses relays and limit switches that is connected to port D.

\subsection{A global system for mobile communication (GSM)}

Global System for Mobile Communication (GSM) modem is a device normally used for transmitter part (Antony et al., 2013).

Basically, GSM is a technology for the digital cellular communication. GSM has been implemented in many mobile communication systems especially mobile phones. It use microwave technology to send the signal that is divided by time, so that the signal information arrive at the destination or receiver system. A GSM modem is a wireless modem that works with a GSM wireless network whereby the basic operation is same as dial-up modem. The differences between GSM wireless and dial-up is that the dial-up modem sends and receives data through a fixed telephone line while a wireless modem sends and receives data through radio waves. The GSM modem requires a SIM card in order to operate (El Sharkawy and Meawad, 2009).

For computers which run Windows OS, AT commands is available at command prompt which can be used to control modems for both GSM modems and dial-up modems. Both also support a common set of standard AT command but GSM modems support further extended set of AT commands (Mukkawar and Sawant, 2015).

In this project, the GSM device as shown in Fig. 2 can supports service line for most of the telecommunication service provider in Malaysia. Example service provider includes Celcom, Maxis, Umobile and Digi. The modem requires a SIM card, and supports both $3 \mathrm{~V}$ and $5 \mathrm{~V}$ SIM cards. The modem used the DB15 to 10-pin adapter cable to connect the modem to the RS-232 header on the circuit (Karim et al., 2009). 


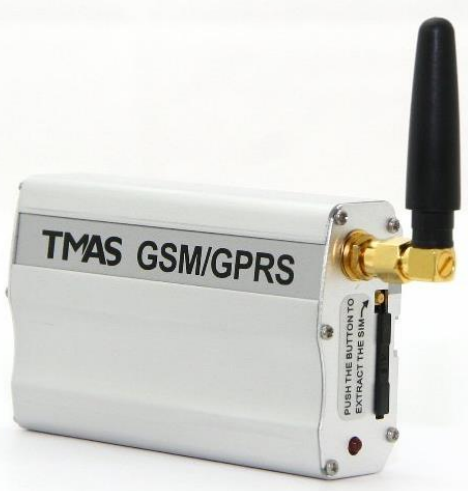

Fig. 2: Global systems for mobile communication (GSM) modem

\section{Results and analysis}

Results and analysis will be discussed further on the section below which cover software, hardware development and also the testing of the prototype.

\subsection{Software analysis}

Several software has been used for in this project in order to check the project process flow. Apart from that, software is also used to draw microcontroller circuit diagram. In this project, PCW compiler is used to translate program into machine language which is in hex format. The hex file then will be uploaded into the microcontroller so that the system could run.

Fig. 3 shows the PCW software used to write the program for the project. This programming software is basically used for communication between PIC microcontroller and mobile phone (transmitter part). After the program had successfully been compiled without any errors, a hex file is generated. This file format also can be used in Proteus software for simulation to test the input/output of the PIC16F877A microcontroller to ensure the project worked as expected.

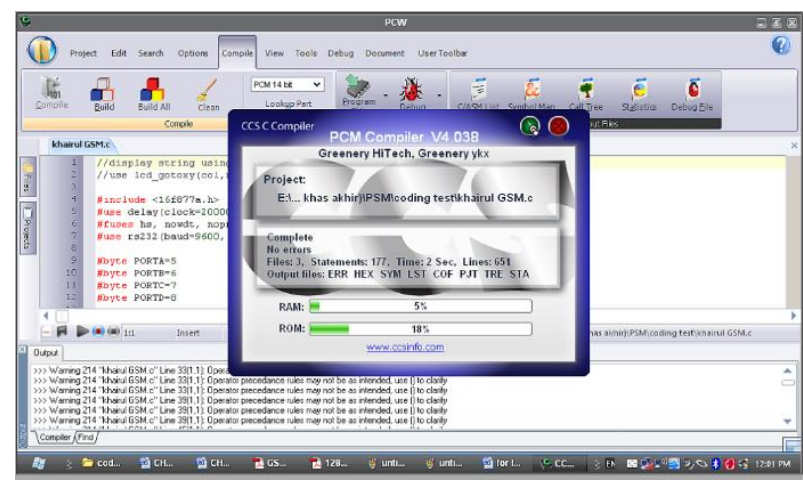

Fig. 3: FCW compiler

\subsection{Simulation result by Proteus 7 Professional}

In Proteus 7 professionals, the programming of PIC16F877A is used for testing to ensure the input/output is worked as good as possible which depicted in Fig. 4. The schematic show the overall circuit involving PIC16F877A microcontroller and communication interface MAX323 which is used for interfacing to GSM modem. The desired program will then be uploaded into PIC16F887A chips to test programming efficiency.

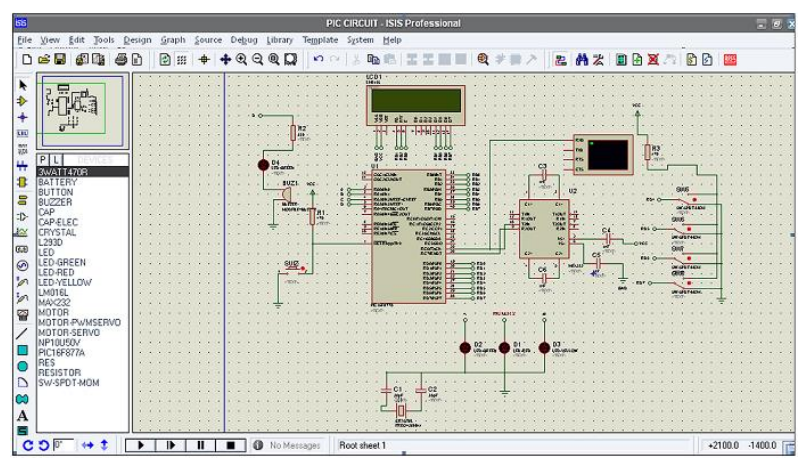

Fig. 4: Circuit in Proteus 7 professional software

After the simulation is run as in Fig. 5, the result worked as expected whereby the LCD appears "Bus Is Not Available" and red LED is activated. Hence, the TX and RX in PIC16F877A indicated that it able to operate properly to activate GSM modem.

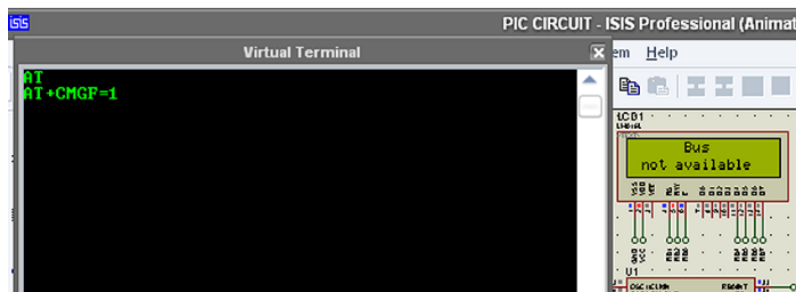

Fig. 5: Result after run the simulation

There are three switches on the board whereby $1 \mathrm{~m}$ switch is used when the bus just started the journey. $2 \mathrm{~m}$ switch is used when the bus at almost $1 \mathrm{~km}$ to the destination while $3 \mathrm{~m}$ switch is used when the bus has arrived at the destination. Fig. 6 shows when $1 \mathrm{~m}$ switch activated.

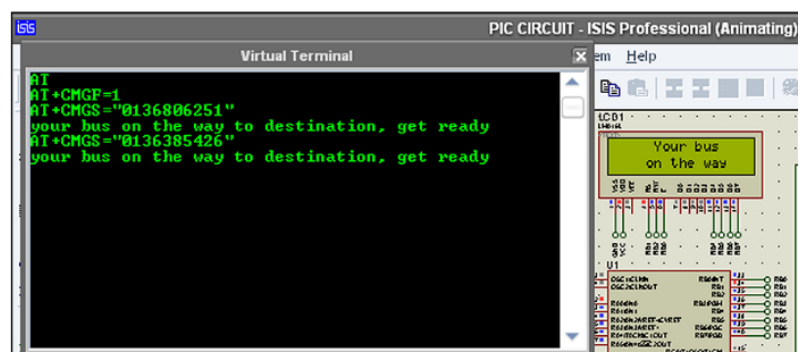

Fig. 6: Simulation result for switch $1 \mathrm{~m}$ active

In Fig. 6, the result had the green LED active in blinking and LCD appear "Bus is on the way" and student also got a message "Your bus is on the way to the destination, please get ready". This shows that the bus is already on the way to the destinations. Hence, students will know that their bus is on the way and get prepared to wait at the bus stop. Fig. 7 shows when switch $2 \mathrm{~m}$ is activated.

In Fig. 7, the result had the yellow LED active in blinking and buzzer is activated and LCD appears "Bus is in the range of $1 \mathrm{~km}$ ". At the same time student will get short message through their hand phone. This case, facilitate student that not to be 
around bus stop to ready to wait bus. 10 minutes is enough for them to come to the bus stop.

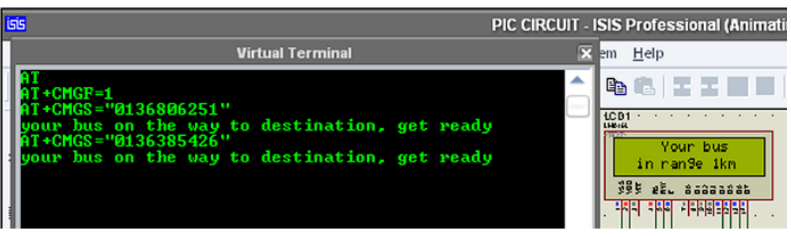

Fig. 7: Simulation result for switch $2 \mathrm{~m}$ active

In Fig. 8, show the final step where the bus driver gives RF input at $3 \mathrm{~m}$ switch to the system to notify that bus already arrived at the destination. During this moment, the green color LED will continuously ON to let users know that bus has arrived.

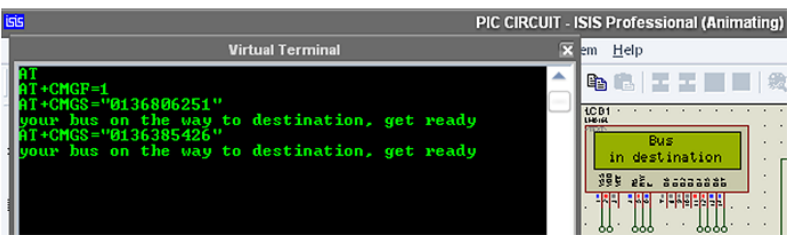

Fig. 8: Simulation result for switch $3 \mathrm{~m}$ active

For auto button process, there is only one switch needed to activate. In this case, bus state off-peak and from the estimated time, bus need about 30 minutes to reach to the destination, whereas within $1 \mathrm{~km}$ distance, its required 10 minutes.

When the switch is set to auto as indicated in Fig. 9, the display will show output LCD "Your bus will arrive in 30 minutes", after 20 minutes of travel time (Fig. 10), the LCD display will then show the notification "Your bus will arrive in 10 minutes" and at the same time, student will get SMS message at their hand phone. After complete 30 minutes, the bus is expected to reach to the destination and the LCD will show "Your bus is in destination" such as in Fig. 11.

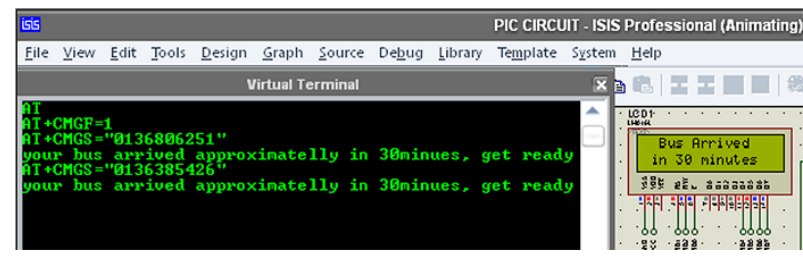

Fig. 9: Simulation result for switch auto starting

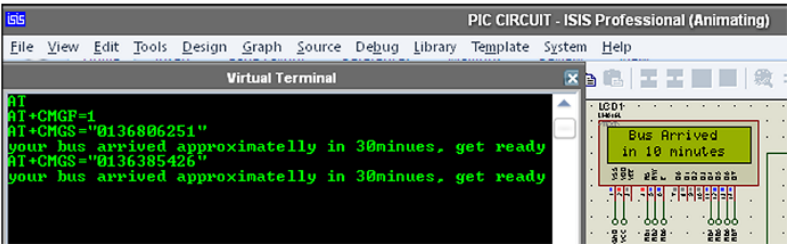

Fig. 10: Simulation result for switch auto after 20 minutes

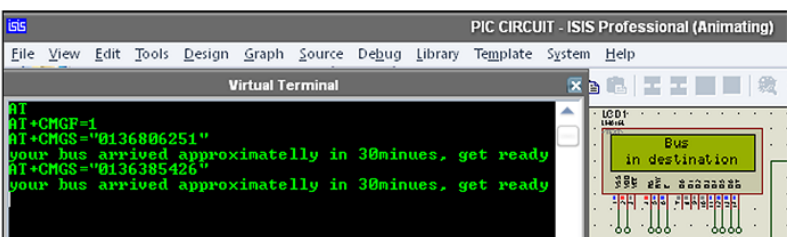

Fig. 11: Simulation result for switch auto after 30 minutes
As shown in simulation result before, there were three switches whereby switch $1 \mathrm{~m}$ to indicate when the bus just started the ride, $2 \mathrm{~m}$ switch, when the bus almost $1 \mathrm{~km}$ to destination while $3 \mathrm{~m}$ switch to inform when the bus has arrived to destination. Fig. 12 depicts the starting of the program, whereby switch $1 \mathrm{~m}$ has activated then the LCD appear information "Your bus on the way" and also blinking green LED.

When the switch $2 \mathrm{~m}$ is activate, the LCD will appear "Your bus is in the range of $1 \mathrm{~km}$ " and also blinking the yellow LED as shown in Fig. 13. At the same time, the buzzer had activated for $10 \mathrm{sec}$ to alert students to get ready. Within this period also the student got message "Your bus is on way to the destination, please get ready" as shown in Fig. 14.

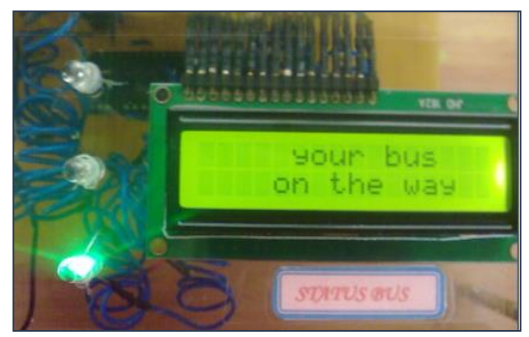

Fig. 12: Hardware result for $1 \mathrm{~m}$ active

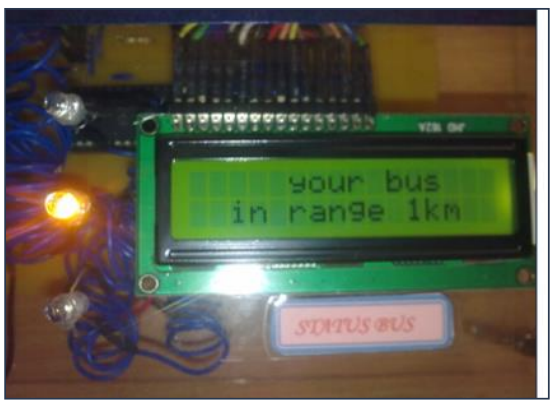

Fig. 13: Hardware result for $2 \mathrm{~m}$ active

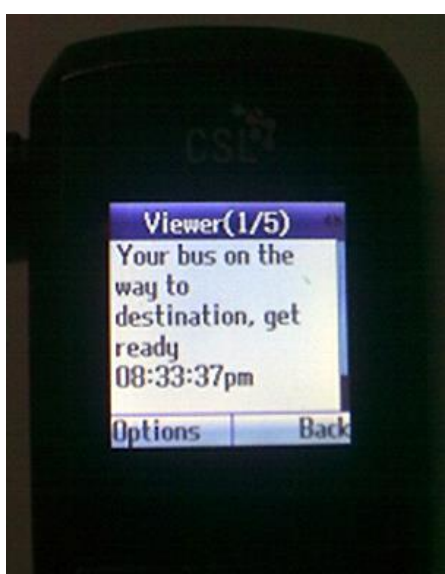

Fig. 14: Result when message received from GSM modem for manual system

When the switch $3 \mathrm{~m}$ is activate, the LCD will show "Bus is in destination" while green LED will turn $\mathrm{ON}$ to indicate that bus has arrived at the destination. Fig. 15 shows the result when switch $3 \mathrm{~m}$ is activate.

When the button is switch to auto mode, bus state off-peak and from the simulation, time required for bus to arrive at destination is about 30 minutes, 
whereas for $1 \mathrm{~km}$ distance it only need 10 minutes. On hardware implementation, when the switch auto is activate, the LCD appears "Bus will arrive in 30 minutes" hence the green LED will blink. Fig. 16 shows the results.

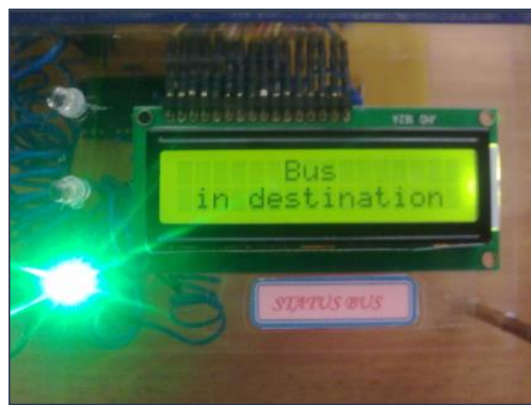

Fig. 15: Hardware result for $3 \mathrm{~m}$ active

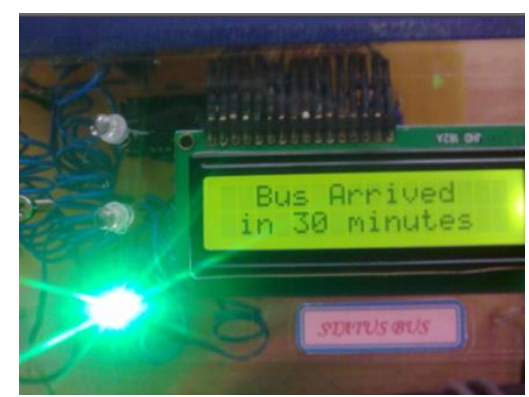

Fig. 16: Hardware result for auto active

Fig. 17 shows text "Bus will arrive in 10 minutes" after 20 minutes of journey and yellow LED will blink. The 20 minutes allocated time is based on estimation during simulation. At the same time, the buzzer had activated for $10 \mathrm{sec}$, hence simultaneously students will receive SMS notification "Your bus will be arrived approximately in 10 minutes, please get ready" as shown in Fig. 18.

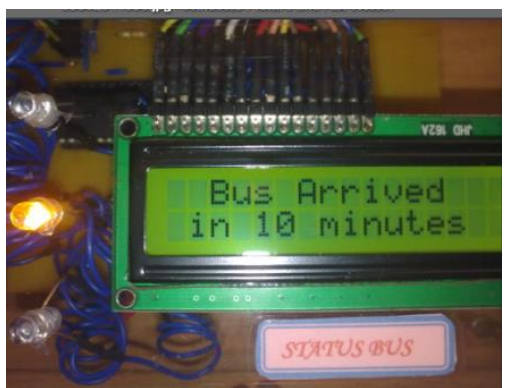

Fig. 17: Hardware result after 20 minutes

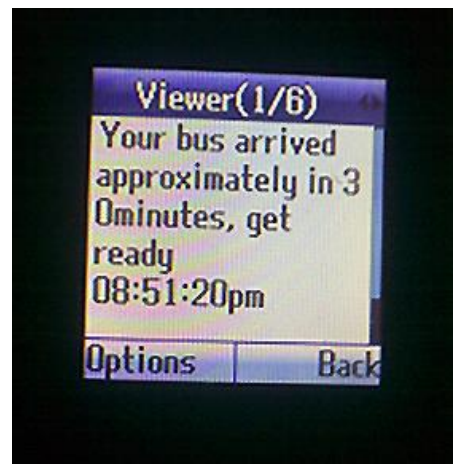

Fig. 18: Result got message from GSM modem for auto system
After 30 minutes, the result show on LCD "Your bus is in destination" and the green LED turn ON as shown in Fig. 19.

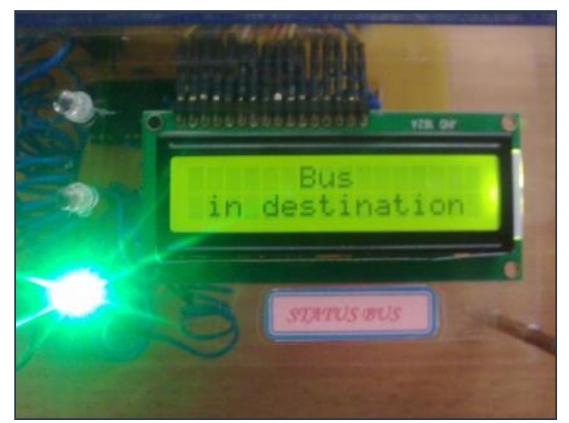

Fig. 19: Hardware result after 30 minutes

\section{Conclusion}

The objective of this project is to build a system that could help reduced student waiting time for university shuttle bus. The system had utilize microcontroller (PIC16F877A) with supporting component such as LCD and LED as indicator as well as GSM system to disperse the information on the current location of the bus to the receiver (students and LCD display at waiting platform). The system has successfully tested on software simulation and hardware implementation and hence it has works as expected.

\section{References}

Ananthanarayanan N (2013). Intelligent vehicle monitoring system using wireless communication. In the International Conference on Advances in Technology and Engineering, IEEE, Mumbai, India: 1-5. https://doi.org/10.1109/ICAdTE.2013. 6524722

Antony AM, Aswathy R, and Keerthana KH (2013). 3G ATM. In the International Conference on Current Trends in Engineering and Technology, IEEE, Coimbatore, India: 421-423. https://doi.org/10.1109/ICCTET.2013.6676003

El Sharkawy BF and Meawad F (2009). Instant feedback using mobile messaging technologies. In the $3^{\text {rd }}$ International Conference on Next Generation Mobile Applications, Services and Technologies, IEEE, Cardiff, Wales, UK: 539-544. https://doi.org/10.1109/NGMAST.2009.93

Giurgiutiu V and Lyshevski SE (2016). Microcontrollers for sensing, actuation and process control. In: Giurgiutiu V and Lyshevski SE (Eds.), Micromechatronics: Modeling, analysis, and design with MATLAB: 727-884. CRC Press, Boca Raton, USA.

Hao Y and Foster R (2008). Wireless body sensor networks for health-monitoring applications. Physiological Measurement, 29(11): 27-56.

Juhari MNZ and Mansor H (2016). IIUM bus on campus monitoring system. In the International Conference on Computer and Communication Engineering (ICCCE), IEEE, Kuala Lumpur, Malaysia: 138-143. https://doi.org/10.1109/ ICCCE.2016.40

Karim J, Amat WMABW, and Razak AHA (2009). Car ignition system via mobile phone. In the International Conference on Future Computer and Communication, IEEE, Kuala Lumpar, Malaysia: 474-476. https://doi.org/10.1109/ICFCC.2009.116

Lau ECW (2013). Simple bus tracking system. Journal of Advanced Computer Science and Technology Research, 3(1): 60-70. 
Available online at: https://www.sign-ific-ance.co.uk/index. php/JACSTR/article/view/403/406

Misran MH, Said MM, Othman MA, Sulaiman HA, Aziz MA, Mustaffa I, and Zainudin MNS (2014). Design and development of RFID based Elevator. In the International Symposium on Technology Management and Emerging Technologies, IEEE, Bandung, Indonesia: 252-257. https://doi.org/10.1109/ ISTMET.2014.6936515
Mukkawar MR and Sawant SD (2015). Energy efficient automation system with smart task scheduling. In the International Conference on Computing Communication Control and Automation, IEEE, Pune, India: 1003-1007. https://doi.org /10.1109/ICCUBEA.2015.198

Peatman JB (1997). Design with PIC microcontrollers. Simon and Schuster Trade, New York, USA. 